\title{
Micosis fungoide, variedad papular
}

\author{
Mycosis fungoides, papular variety \\ María Antonieta Domínguez Gómez, ${ }^{*}$ José Alberto Ramos Garibay, ${ }^{\ddagger}$ \\ María José García Alonso, ${ }^{\S}$ Tania Raisha Torres Victoria"
}

RESUMEN

La micosis fungoide es la manifestación más común del linfoma de células T a nivel cutáneo. En la actualidad existen diferentes variedades clínicopatológicas. La variante papular fue recientemente descrita. Su evolución y pronóstico varían dependiendo del tiempo de evolución, clasificándose en micosis fungoide papular de «inicio temprano o de inicio tardío". En este artículo, se comunica el caso de una mujer de 21 años de edad quien acudió a consulta por presentar neoformaciones de aspecto papular de inicio temprano, en quien se realizó el diagnóstico ya mencionado, evolucionando en forma favorable con el tratamiento prescrito.

Palabras clave: Micosis fungoide, variedad papular, linfoma cutáneo de células $T$.
ABSTRACT

Mycosis fungoides is the most common manifestation of T-cell lymphoma at the cutaneous level. At present there are different clinical-pathological varieties. Papular variant was recently described. Its evolution and prognosis vary depending on the time of evolution, being classified as papular mycosis fungoides of "early onset, or late onset». In this article we report the case of a 21-year-old female patient who came to a consultation due to presenting early-onset papular neoformations, diagnosed as papular micosis fungoides, who evolved favorably with the prescribed treatment.

Keywords: Mycosis Fungoides, papular variety, cutaneous T-cell lymphoma.

\section{INTRODUCCIÓN}

La micosis fungoide (MF) se considera la forma clínica más frecuente de linfoma cutáneo de células T. Alibert en 1806 describió por primera vez la forma clásica en placas, y en 1870 Bazin señaló la progresión clínica de la enfermedad a través de los estadios de manchas a placas, y después a tumores. Lutzner en 1971 fue el primero en describir la célula típica de la MF, y Edelson en 1973 estableció que esta célula pertenecía a la línea de linfocitos T. En la actualidad, existen más de 50 variantes clínico-patológicas descritas. Las presentaciones atípicas de las fases tempranas retrasan el diagnóstico, ya que tienden a imitar otros padecimientos inflamatorios. La variante papular fue descrita por primera vez en 2005; cuenta con escasos reportes en la literatura internacional. ${ }^{1}$

Ésta afecta comúnmente a hombres entre los 31 y los 61 años de edad, con una media de 45 años. Clínicamente se puede clasificar en dos tipos, según el curso de aparición. Si hay lesiones típicas de MF antes de la aparición de las neoformaciones de aspecto papular, indica progresión, con un curso más agresivo y peor pronóstico. Pero si las lesiones de aspecto papular ocurren como manifestación inicial, sin evidencia previa de manchas, entonces se consideran una manifestación temprana, con un pronóstico similar a la fase de mancha de la enfermedad. ${ }^{2}$

\footnotetext{
* Jefe del Servicio de Fototerapia.

¥ Subjefe del Servicio de Dermatopatología.

$\S$ Residente del tercer año de Dermatología.

" Residente del segundo año de Dermatología.

Citar como: Domínguez GMA, Ramos GJA, García AMJ, Torres VTR. Micosis fungoide, variedad papular . Rev Cent Dermatol Pascua. 2021; 30 (2): 96-100. https:// dx.doi.org/10.35366/101180 


\section{ETIOPATOGENIA}

La MF se caracteriza por la infiltración de linfocitos T en la piel, lo cual se manifiesta clínicamente por la presencia de manchas, placas y tumores. Se han descrito tres componentes alterados en el desarrollo de los linfomas de células $T$ : alteración en la regulación de las células $T$, progresión del tumor y respuesta antitumoral. Posterior al reclutamiento de células $T$ propias de la piel en la dermatitis por contacto, por ejemplo, se presenta un aumento de células reactivas, con su posterior eliminación a través de la muerte celular programada (apoptosis) al detenerse el estímulo desencadenante. En el caso de los linfomas, las células $T$ malignas entran en el ciclo celular y se dividen en la piel, pero aparentemente no son eliminadas. De esta forma, estas células sufren un proceso de expansión clonal alterado. Se sugiere que lo anterior se debe a que las células de los linfomas parecen tener un defecto en el mecanismo disparador de la apoptosis, o bien, pueden presentar una falla en la liberación de las proteasas que median la muerte celular programada. Los estudios más recientes sobre progresión tumoral (desde pólipos colónicos hasta cáncer de colon) han demostrado que la transformación en un fenotipo maligno sigue un patrón de mutación celular, lo cual se traduce a nivel histopatológico con la presencia de atipias. En la evolución precoz de la mayor parte de los linfomas, las células malignas son pequeños linfocitos indistinguibles de los no malignos. En la acumulación anaplásica de este eje de transformación, las células tumorales se vuelven más grandes, con citoplasma en general más abundante, con núcleos de apariencia pálida y nucleólos prominentes.

Las lesiones precoces de linfomas de células T están con frecuencia infiltradas por linfocitos $T$ citotóxicos CD8+. Estas células T alteradas dependen de la epidermis para su fase de crecimiento y maduración (epidermotropismo), utilizando los factores de crecimiento. Después, parecen surgir subclonas que manifiestan disminución progresiva de sus requerimientos por los factores epidérmicos, y muestran extensión vertical en paralelo con la diseminación sistémica. Los estudios de cariotipo realizados en células $T$ neoplásicas de pacientes con linfoma cutáneo de células $T$ revelaron alteraciones físicas dentro de los cromosomas de cada paciente, con la subsecuente producción de mitosis aberrantes observadas en las subclonas producidas. Esta clonalidad aberrante es pieza clave para el desarrollo de la enfermedad.

Los estudios epidemiológicos efectuados en Norteamérica evidencian que los pacientes con MF tienen elevada incidencia de alergias y de infecciones micóticas y víricas, en comparación con grupos control, y también detectaron que muchos de ellos son empleados de industrias petroquímicas que producen pesticidas, solventes, vapores, detergentes desinfectantes, tabaco, analgésicos, tiazidas, tranquilizantes, o de aquéllas que elaboran metales, maquinaria o productos textiles.

Otros factores que desencadenan la serie de acontecimientos ya descritos, además de los mencionados en el párrafo anterior, son: factores hormonales, defectos en las células de Langerhans, influencia genética, infección por virus humano linfotrópico tipo-1. Cualquiera de estos estímulos ocasiona una expansión clonal atípica de células CD4 con ausencia de antígenos típicos, principalmente CD7, CD5 o CD2. Estas células son atraídas a la epidermis por los queratinocitos, acumulándose en la dermis, formando agrupaciones alrededor de las células de Langerhans, estructura conocida como «microabscesos de Pautrier».

\section{CUADRO CLÍNICO}

Esta variedad de MF se manifiesta clínicamente por la presencia de neoformaciones de aspecto papular, eritematosas, pequeñas, que varían de 1 a $10 \mathrm{~mm}$, con escama leve en su superficie, no hay manchas. Algunas veces confluyen formando placas.

Se localizan en tronco, extremidades superiores o inferiores, principalmente a nivel de muslos, de manera simétrica. El tamaño de las áreas afectadas oscila entre 3 y $6 \mathrm{~cm}^{3}$

El diagnóstico se basa en los siguientes criterios propuestos: 1) presentación clínica con múltiples neoformaciones de aspecto papular persistentes; 2) ausencia de manchas y/o placas preexistentes de MF convencional (aunque pueden presentarse durante el curso de la enfermedad); 3) características histológicas de MF temprana; y 4) ausencia de tropismo por estructuras anexiales. ${ }^{4}$

Entre los principales diagnósticos diferenciales se encuentran: papulosis linfomatoide tipo $B$, pitiriasis liquenoide varioliforme aguda (PLEVA) y pitiriasis liquenoide crónica. ${ }^{5}$ Clínicamente, a diferencia de la $\mathrm{MF}$, en un cuadro de papulosis linfomatoide, las lesiones tienden a ser recurrentes o sufren regresión espontánea, a veces cursan con ulceración, necrosis o formación de costras en el centro, y suelen dejar una cicatriz de aspecto varioliforme. En la histopatología, las lesiones con frecuencia son idénticas a las de la MF papular, con epidermotropismo y ocasionalmente tropismo hacia los anexos, presencia de un infiltrado 
subepidérmico liquenoide en banda, además de microabscesos de Pautrier; la inmunopositividad para CD30 suele ser variable. ${ }^{6}$ PLEVA es una dermatosis rara, idiopática, presente en niños mayores o adultos jóvenes, clínicamente se manifiesta con lesiones $<5$ $\mathrm{mm}$ de diámetro, con morfología variable: pápulas con escama o pápulo-vesículas con costras. Este cuadro se resuelve de manera espontánea en algunos meses o años. A nivel histopatológico es diferente de la MF papular por la presencia de paraqueratosis y espongiosis focal, neutrófilos intracorneales con queratinocitos necróticos e infiltración de células $T$, daño de interfase $e$ infiltrado linfocitario en banda, además de extravasación de eritrocitos en dermis y ocasionalmente epidermis. La forma crónica de pitiriasis liquenoide es una variedad con el mismo patrón clínico; en el ámbito histológico con menos costras, neutrófilos y queratinocitos necróticos. ${ }^{7}$

Cada caso se estadifica con base en el sistema TNMB (tumor size, lymph node, metastasis, blood, por sus siglas en inglés).

El abordaje diagnóstico incluye exploración física minuciosa, biopsia de piel, biometría hemática con diferencial, análisis de células de Sézary, química sanguínea y radiografía de tórax. En caso de presentar linfadenopatía, se deberá de solicitar tomografía computarizada de tórax, abdomen y pelvis, o tomografía por emisión de positrones (PET), además de biopsia incisional de ganglios para diagnóstico y estadificación.

\section{TRATAMIENTO}

El tratamiento inicial depende del estadio clínico y la diseminación de la enfermedad. En caso de presen-

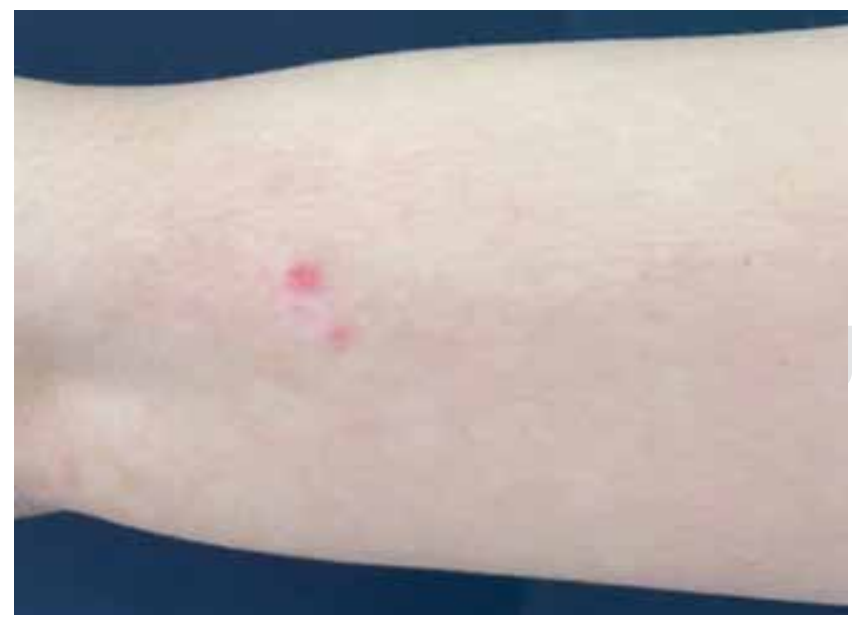

Figura 1: Lesiones en cara posterior de brazo izquierdo.
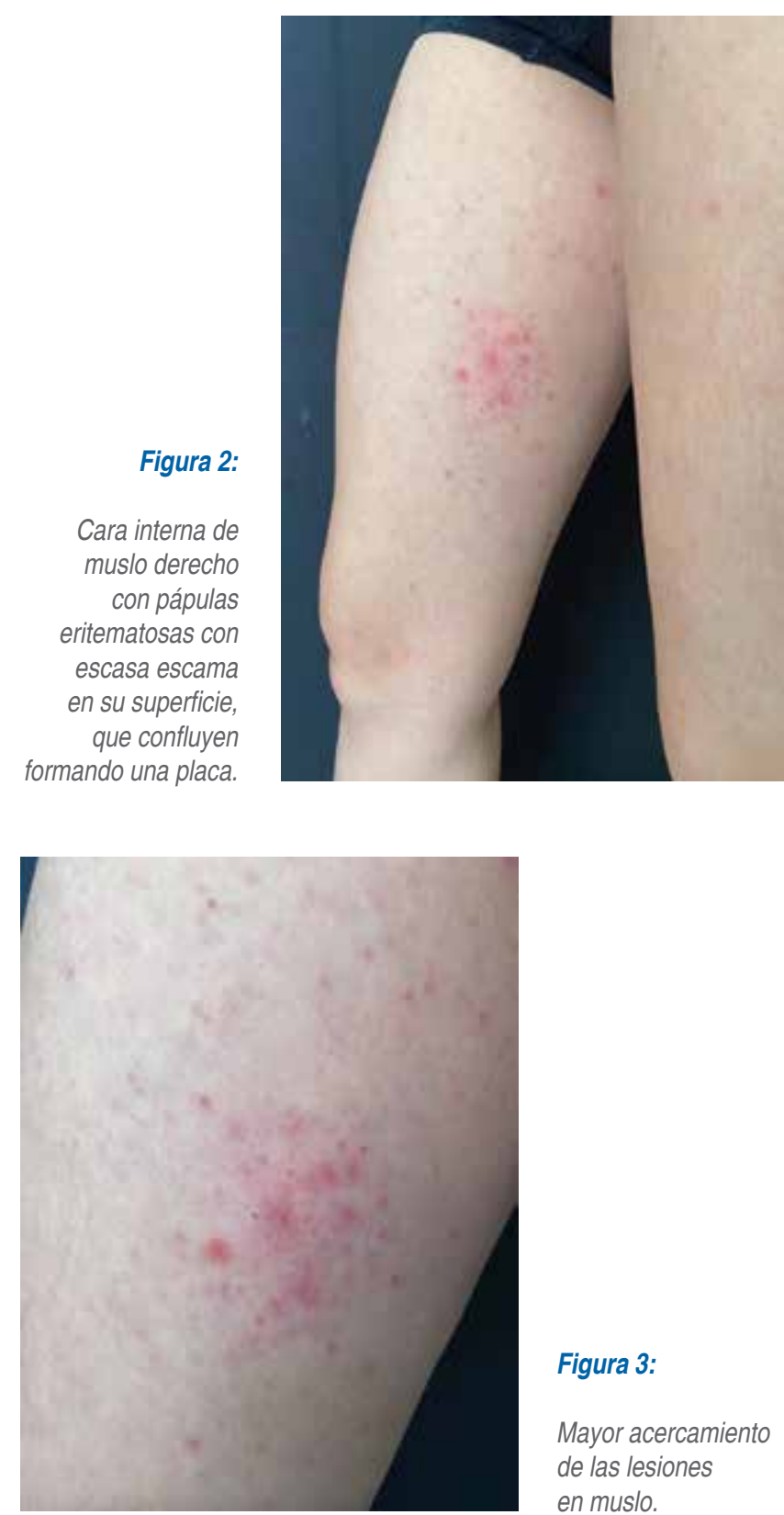

Figura 3:

Mayor acercamiento de las lesiones en muslo.

tación inicial con manchas, placas o neoformaciones de aspecto papular en menos de $10 \%$ de la superficie corporal (estadio IA), se prefiere tratamiento tópico, principalmente a base de corticosteroides de alta 0 mediana potencia, con los que se obtiene respuesta favorable en más de $90 \%$; retinoides tópicos (bazaroteno o tazaroteno), imiquimod, quimioterapia tópica (mostaza nitrogenada, carmustina) o fototerapia (UVB o PUVA). En estadios avanzados (estadios IB-IV) se requieren tratamientos sistémicos, entre éstos se puede optar 


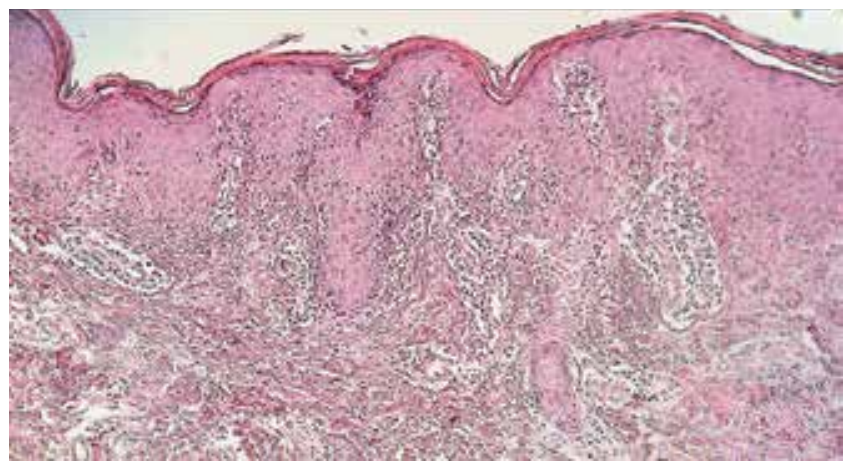

Figura 4: Epidermis con acantosis más o menos regular a expensas de los procesos interpapilares. En dermis superficial y media un infiltrado linfocitario moderado (H\&E 4x).

por fotoforesis extracorpórea, interferón alfa o gamma, retinoides sistémicos, quimioterapia o inhibidores de histona desacetilasa. ${ }^{8}$

\section{CASO CLÍNICO}

Mujer de 21 años, originaria y residente de la Ciudad de México, de ocupación estudiante. Acude por presentar dermatosis diseminada a extremidades superiores e inferiores; de la primera afecta cara posterior de brazo izquierdo, de la segunda extremidad inferior derecha compromete la cara interna del muslo, en su tercio medio, bilateral, asimétrica. De aspecto monomorfo, se trata de una dermatosis constituida por 13 neoformaciones de aspecto papular, de tamaño variable, eritematosas, algunas con leve escama en su superficie, que confluyen formando una placa de aproximadamente 8 $\mathrm{cm}$, mal delimitada. De evolución crónica, asintomática (Figuras 1 a 3).

Al interrogatorio refiere haber iniciado dos años antes con «granitos» en brazos y piernas, asintomáticos. Acudió con varios médicos particulares, quienes prescribieron múltiples tratamientos, incluyendo dicloxacilina, ciprofloxacino, loratadina, desloratadina, cetirizina, ketotifeno, permetrina, betametasona, clotrimazol y gentamicina, sin notar mejoría. Como antecedentes heredo-familiares refiere abuela y tío materno con diabetes mellitus tipo 2, y un hermano finado por linfoma de Hodgkin. Resto de antecedentes personales patológicos sin importancia para su padecimiento actual.

Se realizó biopsia incisional, las imágenes histopatológicas mostraron epidermis con acantosis más o menos regular a expensas de los procesos interpapilares. En dermis superficial y media se aprecia infiltrado linfocitario moderado (Figura 4). A mayor aumento, se observa invasión de los linfocitos hacia la epidermis (epidermotropismo) (Figura 5). En algunos sitios, los linfocitos tienden a formar microabscesos de Pautrier (Figura 6). El tratamiento prescrito en este caso consistió en la aplicación de desonida crema una vez al día, por cuatro semanas, con posterior aplicación de toques con esencia de lima, y exposición a luz de sol (puvasol) durante media hora por tres semanas; la paciente evolucionó en forma favorable, con disminución en el tamaño de las lesiones y en la intensidad de la infiltración de la placa, aunque éstas aún persisten.

\section{COMENTARIO}

Consideramos de interés publicar este caso clínicopatológico al ser la MF papular una variedad rara, descrita hace relativamente poco tiempo. Hasta la fecha se han publicado 28 casos. En la revisión de la literatura de dichos casos, la media de edad de los casos estudiados fue de 53 años (rango de 13 a 83). En $90 \%$ se reportó afectación solamente de tronco y/o extremidades superiores e inferiores. En $7 \%$ se observó sólo afectación de extremidades superiores, y en $3 \%$ de glúteos. En cuanto al tiempo de seguimiento, los lapsos oscilaron entre los 10 meses y los 19.6 años. La mayoría presentó enfermedad estable (46\%), remisión completa (28\%), defunción por enfermedad a los cuatro y 16 años (7\%), y enfermedad progresiva a los 17 y 25 años después del diagnóstico (7\%), en $7 \%$

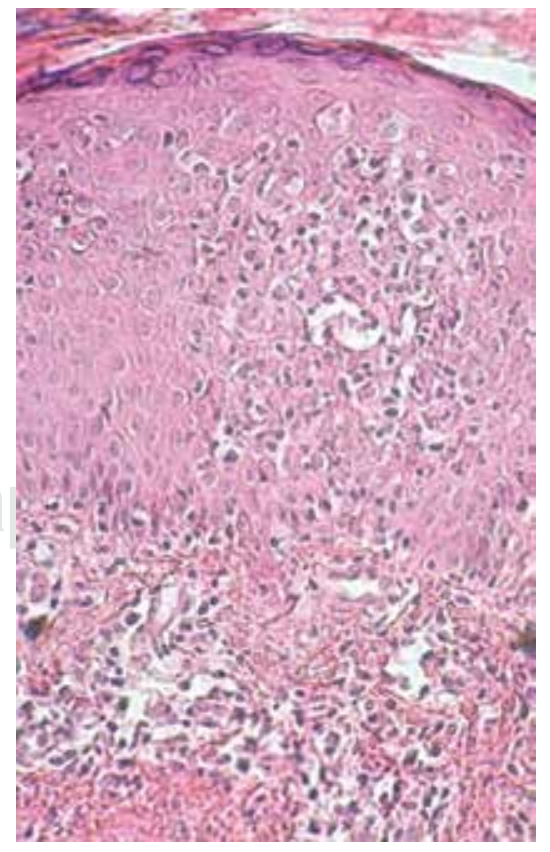

Figura 5:

A mayor aumento, se observa invasión de los linfocitos hacia la epidermis o epidermotropismo (H\&E 10x). 


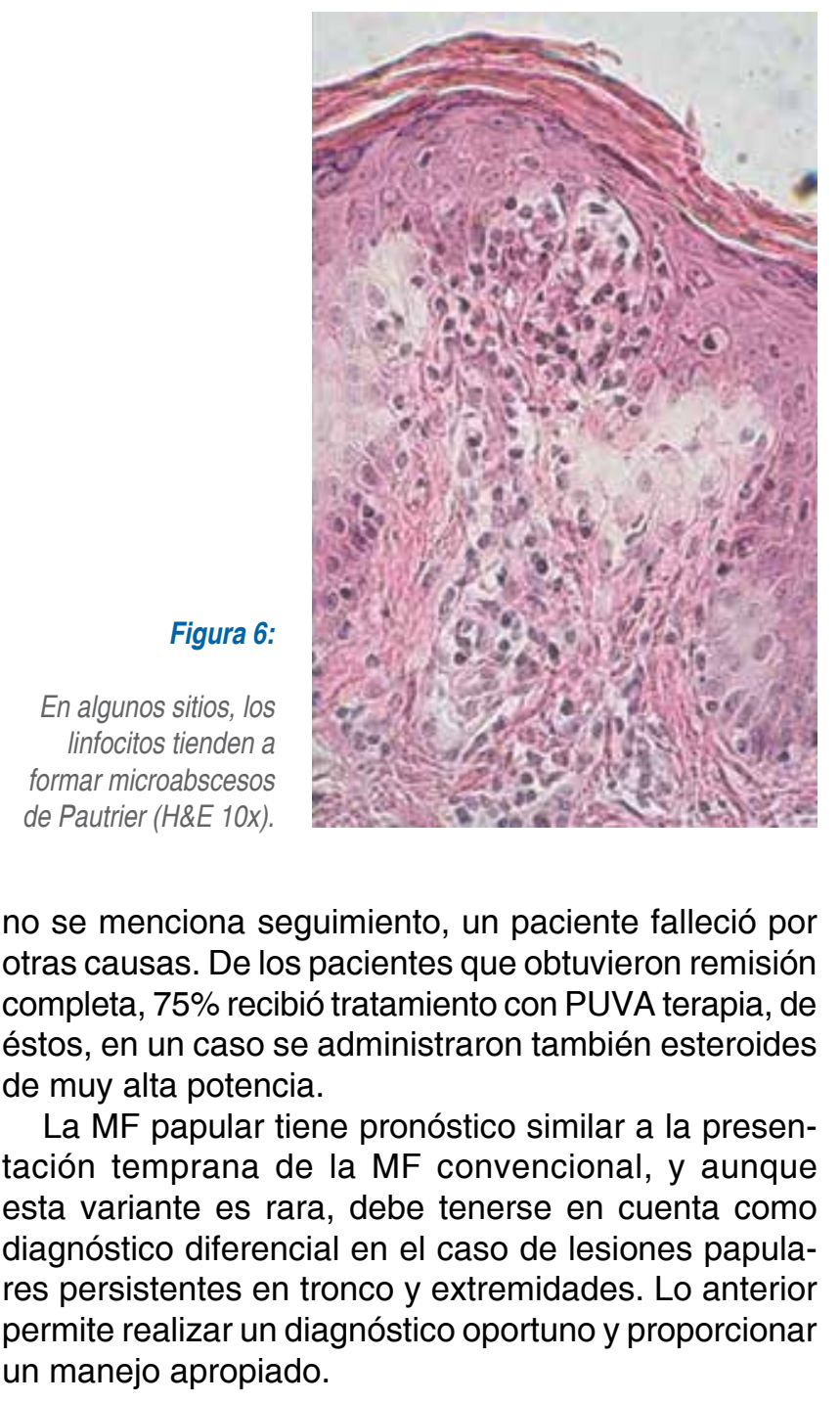

\section{REFERENCIAS}

1. Kodama K, Fink-Puches R, Massone C, Kerl H, Cerroni L. Papular mycosis fungoides: a new clinical variant of early mycosis fungoides. J Am Acad Dermatol. 2005; 52: 694-698.

2. Kim SJ, Schaffer A, Lee HY, Seo JY, Park HJ. A case of papular mycosis fungoides: a new clinical variant of early mycosis fungoides. Ann Dermatol. 2016; 28: 383-384.

3. Liu ZH, Wang YL, Chen SY, Zheng JH, Qiao G, Shen H, et al. Papular mycosis fungoides: a new clinic variant of early and benign mycosis fungoides? J Clin Oncol. 2011; 29: e381-383.

4. Saggini A, Fink-Puches R, Cota C, Lora V, Potzinger $\mathrm{H}$, Massone $\mathrm{C}$ et al. Papular mycosis fungoides is a distinctive variant of early-stage mycosis fungoides. Am J Surg Pathol. 2019; 43: 1129-1134.

5. Santamarina-Albertos A, Muñoz-Martínez R, Álvarez-Gago T, Miranda-Romero A. Micosis fungoide papular en las piernas, a propósito de un caso. Actas Dermosifiliog. 2014; 105: 87-89.

6. Vonderheid EC, Kadin ME, Telang GH. Commentary about papular mycosis fungoides, lymphomatoid papulosis and lymphomatoid pityriasis lichenoides: more similarities than differences. J Cutan Pathol. 2015; 43: 303-312.

7. Martorell-Calatayud A, Botella-Estrada R, Sanmartín-Jimenez O, Requena C, Guillén-Barona C, Sangüeza OP. Papular mycosis fungoides: two new cases of a recently described clinicopathological variant of early mycosis fungoides. J Cutan Pathol. 2010; 37: 330-335.

8. NCCN Clinical Practice Guidelines in Oncology. Non-Hodgkin's lymphomas. Nat Compr Canc Netw [On Line]. 2015[cited 2021] Available in: https://www2.tri-kobe.org/nccn/guideline/hematologic/ nhl/english/foll.pdf

\section{Correspondencia:}

Dra. María Antonieta Domínguez Gómez

Dr. Vértiz Núm. 464 Esq. Eje 3 Sur,

Col. Buenos Aires, 06780,

Alcaldía Cuauhtémoc, CDMX.

Tel. 55-5519-6351.

E-mail: dominguez035@yahoo.com.mx 